\title{
ACTUALIDAD DE GOETHE
}

\author{
Fernando Magallanes Latas
}

\section{EL GENIO INABARCABLE}

La universalidad y extraordinaria magnitud de Johann Wolfgang von Goethe se hace prácticamente inabarcable si lo que se quiere es trazar un perfil de él. Así es, su actividad aglutina política, pintura y dibujo, ciencia y literatura. Y sólo por lo que se refiere a esta última, poesía, narrativa, teatro, ensayo y correspondencia epistolar, o sea los distintos géneros, fueron objeto de su atención. Goethe, además, es el único escritor alemán que da nombre a toda una época de la cultura: Goethezeit, es decir la etapa que comprende Sturm und Drang, Klassik y Romanticismo; y precisamente es de los pocos dramaturgos del citado movimiento prerromántico -por no decir casi el único- cuyo teatro perdura en los repertorios alemanes y extranjeros.

De otro lado, el mar de bibliografía, con opiniones de todo tipo, es tal que cualquier mínimo aporte que se quiera hacer obliga a un estudio detenido de infinidad de trabajos; además, naturalmente, de Goethe, como figura universal que es, proliferan en Alemania y fuera de allí su teatro, obras filmadas -como Werther-, recensiones críticas, artículos periodísticos sobre él y su obra, foros, etc.; de ahí que se imponga la necesidad de acotar con la mayor precisión posible el aspecto sobre el que gire una incursión en torno a Goethe; y, en este sentido, los límites aquí establecidos son los que se desprenden de la única atención a la vertiente espectacular, con exclusión del mundo del libro, traducciones, etc. Por lo tanto, sin entrar en el estudio ni en la consideración de la obra dramática de Goethe, ya sea desde la perspectiva de la Historia de la Literatura, ya en lo que respecta a cuestiones de tipo teórico, me fijaré en su vigencia -en especial la de las grandes composiciones dramáticasen los escenarios teatrales de los últimos tiempos a mero título ejemplificativo de lo mucho aportado por el Goethe escritor, y a fin de ver qué huella deja el teatro goethiano en la actualidad. Para ello, los ejemplos que citaré son representativos y significativos, pero lógicamente no es posible aspirar a la exhaustividad en el breve espacio de un artículo.

El fin perseguido es pues mostrar, a modo de retazos, algunos hitos aplaudidos unánimemente por crítica y público, por los dos polos del receptor literario; de tal modo, la línea 
metodológica que subyace es la correspondiente a uno de los enfoques propuestos por la Estética de la Recepción: el efecto que produce la obra de otra época en la actualidad. ${ }^{1}$

\section{VINCULACIÓN AL ARTE ESCÉNICO}

Ya en su infancia a Goethe le gustaba el teatro de títeres, algo por lo demás nada sorprendente pues con frecuencia los niños sienten inclinación hacia ese tipo de espectáculo; pero, en todo caso, se ha dicho que quizá influyera en ello el regalo que le hizo un pariente: un pequeño escenario de marionetas, conservado aún hoy en su casa natal de Frankfurt. Más llamativo es, sin embargo, que con once años asistiera a representaciones de teatro para adultos; así fue como se familiarizó con obras de Racine o Molière, por ejempo. Y, en torno a los trece años, esbozó ya un drama bíblico sobre la caída de Belsazar, el rey de Babilonia castigado por blasfemo.

Sin duda, pues, el teatro llamó su atención; y hasta tal punto que en algún momento de su última etapa de Frankfurt llegó a decir "si no escribo dramas, me destruyo" (Boerner, 1981: 34). Claro que igualmente podría haberlo dicho en relación a la poesía o respecto de la actividad científica, ocupación ésta por la que, por cierto, hubiera deseado pasar a la posteridad. Sin embargo, la referencia la hizo al teatro; señal evidente de su preferencia y predisposición hacia la literatura dramática. Baste recordar su Wilhelm Meisters theatralische Sendung, aquella novela autobiográfica, de 1777, cuyo protagonista se une a una compañía de cómicos como director y asesor escénico.

En nada extraña, por tanto, que Goethe escribiera numerosos bocetos dramáticos, algunos desgraciadamente destruidos por él mismo, como fue el caso de una tragedia sobre César que optó por quemar. En otros casos, nos legó fragmentos, como el drama Prometeo, de 1773. Nombres que también le rondaron la cabeza fueron los de Mahomet o Sokrates, personalidad ésta importante además desde el punto de vista de influencia sobre él. ${ }^{2}$ Igualmente, de un drama al estilo de Iphigenie, Elpenor, de 1781, sólo concluyó un fragmento; y otro compuesto por su amigo Schiller, Demetrius, tuvo intención de completarlo pero se quedó sólo en eso, en la intención. Afortunadamente se conservan otras piezas breves completas: así, un Concierto dramático, las coplas de Das Jahrmarktsfest von Plundersweilen,

\footnotetext{
${ }^{1}$ Bien entendido que lo que sigue no intenta ser otra cosa que el esbozo de una posible investigación aún por hacer, y que habría de tener en cuenta elementos de análisis como son, entre otros, el horizonte de expectativas o la distancia estética, o incluso cuestiones que van más allá de la perspectiva recepcional clásica, como el "destinatario como fuerza productiva literaria" (Zimmermann, 1974: 18). De igual modo que no sólo la "conservación pasiva", sino la recepción activa que expande su proyección sobre la cultura del momento (Moog-Grünewald, 1984: 72) es otra óptica de extraordinario interés. Pero, de momento, el objetivo que aquí se persigue es, como digo, un primer paso en la indagación sobre el tema.

${ }^{2}$ A propósito de esto, el propio Goethe parece que no era muy amigo de indagar acerca de las influencias: “Goethe, quien prefería el ideal de la originalidad y consideraba como 'muy ridículo' la búsqueda de modelos e influencias, arguye, para resaltar la significación de su independencia creadora, una comparación poco tierna, pero muy de acuerdo con el sentido: 'Igualmente se podría peguntar a un hombre bien alimentado por los bueyes, corderos y cerdos que ha comido y le han dado fuerzas... Yo debo mucho a los griegos y los franceses, debo infinitamente a Shakespeare, Sterne y Goldsmith. Sólo que con ello no se han demostrado las fuentes de mi cultura; caería en lo ilimitado y no sería necesario" (Eckermann, 16.12.1828) (Moog-Grünewald, 1984: 88)
} 
Das Fastnachtspiel vom Pater Brey, Satyros, la farsa: Götter, Helden und Wieland, o dos comedias cantadas: Erwin und Elmire y otra, inspirada en la comedia española de capa y espada, y que lleva por título Claudine von Villa Bella.

Pero no terminan aquí las composiciones goethianas para el teatro dentro de lo que cabría calificar como obra menor -y naturalmente con menguada repercusión en la vida cultural contemporánea-. Sin dar cabida a todas, aunque sí a la mayor parte de ellas, un listado de títulos debería iniciarse con su primera aportación de cierta envergadura: Die Laune des Verliebten, de 1767 y representada en 1779. Era ésta una comedia con reminiscencias rococó y que no ocultaba el autobiografismo: la pasión amorosa por Käthchen, es decir, Anna Katharina Schönkopf, hija de un tabernero de Leipzig.

Singular referencia merece Die Mitschuldigen, de 1769. Comedia de su época de Leipzig, que se representó en el año 1777, contiene cierta crítica social y ofrece ya una mayor calidad por el uso que el autor hace de recursos. Por lo demás, se trata de la primera representación de una obra de Goethe en España: en 1892 se escenificó en Madrid con el título Los cómplices.

Aparte de la adaptación de Las aves, de Aristófanes, a su época, después del segundo viaje a Italia, Goethe escribió Der Groß-Cophta, en 1791, comedia con resonancias de la Revolución francesa y en la que se desvelan entresijos de la Corte; la también comedia Der Bürgergeneral, en 1793; e, inconcluso, el drama Die Aufgeregten entre 1793 y 1794. En los tres títulos citados Goethe pone en claro su idea acerca de lo inapropiado de la revolución para subsanar cuestiones de orden político. A mayor abundamiento, dejó otros testimonios en los que resuena su concepción acerca de aquel suceso histórico trascendental: obras de alguna forma ligadas al acontecimiento de la Revolución francesa fueron los fragmentos inspirados en la Antigüedad clásica Nausikaa, de 1787, y Pandora, de 1808.

\section{GOETHE Y EL ESPECTÁCULO TEATRAL}

Si en lo literario, poesía y teatro fueron su vocación más decidida, este último constituyó actividad muy destacada de Goethe, especialmente entre 1771 y 1789 . Cierto que la época acompañaba su inclinación: los decenios postreros del siglo XVIII fueron propicios para la organización de foros sobre la función educadora del teatro, medio idóneo de transmitir ejemplaridad; y, no por casualidad, en el tercio final del siglo se erigen destacados teatros: Hamburgo en 1767, Viena en 1776, Mannheim en 1779, o Berlín en 1786.

Goethe además sentó bases de una teoría dramatúrgica cuando, en el primer escrito en prosa que se conserva de él -el discurso para el día de Shakespeare leído ante su hermana y sus amigos el 14.10.1771-, proclamó el abandono de la estética rococó y de las reglas propias del teatro francés, trazando así las líneas programáticas del futuro Sturm und Drang, distintivo inequívoco de una literatura alemana plenamente autóctona, libre de ataduras y tutelas extranjeras.

Fue, empero, su actividad a pie de escena lo que le entretuvo con más ahínco. En los comienzos de su estancia en Weimar, participó en representaciones de aficionados para la sociedad cortesana, consistentes en improvisaciones, a veces al aire libre. Los textos de 
aquellas exhibiciones se han perdido, pero sabemos que los actores eran miembros de la Corte, oficiales de Palacio, la servidumbre, damas de cámara, pajes y, por supuesto, el propio Goethe que actuaba normalmente en papeles cómicos.

Pero también se representaron en el teatro de aficionados, dirigido por él, otros dramas, como Geschwister, de 1776, comedia burguesa en un acto que, por cierto, se exhibió en Barcelona, en catalán, en 1918; o la comedia cantada, que muestra clara referéncia a su amada Lili Schönemann, Lila, de 1777; o Triumph der Empfindsamkeit, de 1778, fantasía dramática que aún se representó no hace mucho; o, en fin, Jery und Bätely de 1779, y Die Fischerin, de 1781. Al parecer, la técnica que seguía Goethe consistía en coordinar la lectura en común del texto a fin de que los actores memorizasen su papel al tiempo que se familiarizaban con el sentido general y los matices de la pieza.

Sin embargo, su vocación y pasión por la escena, fundamentada en la inmediatez de la transmisión de contenidos sólo entonces posible a través de este medio, le impulsaría a dar el salto del teatro de aficionados al profesional: en 1791 se fundó el Teatro de la Corte, en Weimar, de cuya dirección se hizo cargo. No sin ánimos y apoyo de su amigo Schiller, realzó considerablemente el prestigio del Hoftheater, hasta que en abril de1817, hastiado por las intrigas de la actriz Caroline Jagemann, protegida del duque Karl August, renuncia a la dirección.

\section{VIGENCIA DE LAS GRANDES OBRAS TEATRALES}

Sin duda, es la obra mayor la que tiene una fácilmente constatable vigencia actual en Alemania y fuera de Alemania. Aún hace un par de años se proyectaba en los cines italianos la película Le affinita alettive, adaptación al marco geográfico de Toscana de la novela Die Wahlverwandtschaften, realizada por los hermanos Paolo y Vittorio Taviani. Igualmente alguna otra aportación, como Reineke Fuchs, de 1793, épica burlesca en hexámetros, se adaptó a la escena en las temporadas 86-87/87-88 en el Deutsches Schauspielhaus de Hamburgo, por Michael Bogdanov.

Pero ciñámonos con exclusividad al teatro, al número o frecuencia de las representaciones teatrales (Moog-Grünewald, 1984: 82), como dato que necesariamente ha de tenerse en cuenta cuando de lo que se trata es de ver aspectos de la recepción de un dramaturgo del pasado en la actualidad.

La primera de las grandes obras teatrales, dentro de la fase de Goethe como escritor del Sturm und Drang, es ese drama caballeresco en el que prima la idiosincrasia, lo individual, Götz von Berlichingen, cuya primera versión data de 1771 y la definitiva de 1773 , y que se estrenó en 1774. Pese a su dificultad de adaptación escénica -59 cambios de escenas, sin unidades de tiempo y espacio-, se puede ver en la actualidad. Pero una representación de los últimos tiempos, con excelente acogida por parte de la crítica, tuvo lugar en las temporadas 88-89/89-90 en el Schauspiel de Frankfurt, bajo el título Die geschichte Gottfriedens von Berlichingen mit der eisernen Hand, y con Einer Schleef como director y escenógrafo, quien recibió los mayores elogios de los críticos, al igual que los intérpretes Martin Wuttke y David Bennet. 
Clavigo, de 1774, compuesta a partir de Fragment de mon voyage en Espagne, de Beaumarchais, y representada en 1779 en el recién inaugurado teatro de Mannheim, por su temática española se representó ya en 1931 en Madrid. Obra vigente, que puede verse en los escenarios alemanes, resultó especialmente significativa su escenificación en las temporadas 90-91/91-92, cuando entonces se ofreció al público en el Burgtheater, de Viena, con éxito de los protagonistas Ulrich Mühe, Paulus Manker y Martin Schwarb, y con original escenografía de karl-Ernst Hermann.

Caso más curioso es el de Stella, de 1775, polémica en su momento y una de las obras que más se representa en nuestros días. Sobresalientes fueron las temporadas 88-89/89-90 en el Deutsches Schauspielhaus, de Hamburgo, bajo la dirección de Frank Castorf, considerado precisamente por este trabajo uno de los mejores directores de la temporada. Pero también en los años 90-91/91-92 se escenificó en dos versiones: una en el Schauspielhaus, de Colonia, a partir de una dramaturgia de Günter Krämer y Ulrich Fischer, y con magnífica actuación de la actriz Maria Happel; y otra, la versión del Münchner Kammerspiele, bajo dirección de Thomas Langhoff y escenografía de Jürgen Rose, calificado mejor escenógrafo de la temporada, y en donde el papel femenino corrió a cargo de Sybille Canonica.

En cambio, el caso de Egmont -pieza que relaciona los conceptos de Humanidad y Estado queriendo trascender lo puramente individual, aunque predomine más la presentación de un carácter que la inicial idea del autor de contraponer libertad y opresión- es significativo por su no tan destacada vigencia. Escrita en 1787 y estrenada en 1791, la combinación de prosa y verso yámbico muestra claramente el estadio transitorio de Surm und Drang a Klassik. Pese a que también aquí hay temática española, no es sin embargo precisamente pieza que se prodigue en nuestros teatros -en parte sin duda por la exposición de un sometimiento tenebroso de los Países Bajos-; como -aunque ya no es la agitación escénica de Götz- tampoco en Alemania parece haber grandes hitos. Diríase incluso que cuantitativamente se halla a distancia del resto del teatro goethiano, en lo que a número de escenificaciones se refiere.

Distinta situación la tenemos con respecto a Iphigenie auf Tauris. Drama anímico que muestra la transformación espiritual del joven Goethe al Goethe clásico, la primera versión en prosa, de comienzos de los años de Weimar del autor, fue luego -en 1786- recompuesta en versos yámbicos. Llevada a los escenarios en 1802, la fogosidad y el caos dan paso aquí a esa típica Innerlichkeit, característica de la literatura alemana de siempre, en opinión de Thomas Mann. Humanidad del personaje y necesidad de hallar cada uno en sí mismo las vías de salvación, serían los ejes esenciales de este drama goethiano del que -gracias a la compañía del Burgtheater vienés- pudo disfrutar el público de Roma en 1958. Fechas memorables fueron igualmente los años 1990-91 y 1991-92, cuando -presente en las carteleras del Schillertheater de Berlín- se le dispensó una muy favorable crítica a la joven actriz Gundula Aurich por su trabajo interpretativo.

Torquato Tasso, pergeñado en febrero de 1780 y concluido en 1789, se estrenó en Weimar en 1807. En torno a la psicología del poeta épico renacentista italiano de la corte de Ferrara, mezcla de sueño y realidad, continúa hoy en cartel. En 1994 se representaba en el Schauspiel de Frankfurt; pero ya antes, en 1969 en Bremen y bajo la dirección de Peter 
Stein, tuvo buena acogida; igualmente en las temporadas 88-89/89-90, cuando en Francia se adaptó y dirigió por Bruno Bayen para el Théâtre National de l'Odéon.

Iniciada en 1799, Die natürliche Tochter, primera parte de una trilogía inconclusa sobre la Revolución francesa, fue estrenada el 2.4.1803 en Weimar. Bien representada en las temporadas 90/91-91/92, en el Schauspiel de Bonn, con la intérprete Sandra Flubacher y escenografía y figurines de Peter Schubert, forma parte de los títulos vigentes de Goethe.

Evidentemente, la obra cumbre de Goethe, Fausto, es un caso aparte. Las primeras representaciones de escenas de Faust I datan de 1819, en Berlín; también en París se representó en 1828; y un año después en Braunschweig y Weimar. No muy presente en repertorios españoles, raramente se llevó a escena en la primera mitad de nuestro siglo; a veces incompleto, como fueron los fragmentos que pudieron verse en Madrid y Barcelona en 1932; otras veces en refundiciones libres. ${ }^{3}$ Ya recientemente la situación cambia; y así, en 1997 por ejemplo, tuvo lugar un ciclo de teatro alemán con activa participación del actor y director José Luis Gómez, de manera que en los Festivales de Otoño de aquel año pudo verse en el Teatro Abadía de Madrid, y en adaptación claramente expresionista, un Urfaust dirigido por Götz Loepelmann, bien conocido en los ambientes teatrales berlineses.

Obra de permanente actualidad en Alemania, ${ }^{4}$ es en todo caso la primera parte la que con mucha más frecuencia se ha llevado tradicionalmente a los escenarios, tanto allí como en el extranjero. Fue en 1957 cuando tuvo lugar una de las adaptaciones más singulares, en el Deutsches Schauspielhaus de Hambugo. El director, que a la vez encarnaba el personaje de Mefistófeles, fue Gustaf Gründgens. Inspirándose en el Prólogo en el Teatro que da inicio a la obra, se le ocurrió montar sobre el escenario otro, de títeres, de menores dimensiones en el que se movían los muñecos que representaban la obra. Curiosas resultaron, igualmente, las brujas del final: a guisa de seres extraterrestres actuaban con desenfreno al compás de "boogie-woogie" y "rock-and-roll". Para la comprensión de la originalidad de contenido introducida, se le allanaba el camino al espectador mediante textos -impresos en los programas de mano- de personalidades como Einstein o el físico nuclear Weizäcker; todo ello con el fin de mover a reflexión acerca de la responsabilidad del científico, y en clara referencia a la dificultad de compaginar ciencia y fe. Y es que, si el decorado presentaba raras novedades, como una pila nuclear o la fotografía de una ciudad atómica, precisamente el paso de un avión y un gran estruendo, seguido de la aparición del espeluznante hongo atómico, ponían fin al espectáculo .

Aparte de otras representaciones, como en 1959 la primera parte de Fausto, el Faust II en 1966, en Berlín, etc., también en 1973 la obra se llevó con éxito a las tablas. En esa ocasión y adaptada por Juan Rográ, en Argentina, en el Taller de Garibaldi, donde un año más tarde volvió nuevamente a reponerse bajo dirección de Rodolfo Graziano.

\footnotetext{
${ }^{3}$ Motivo de peso para que los especialistas piensen que la crítica sobre Fausto en España normalmente se haya centrado en el libro, más que en la obra teatral.

${ }^{4}$ Se escenificaron por ejemplo recientemente, en 1997, ambas partes; en 1998 también en Düsseldorf, etc.
} 
Pero fue el año 1975 uno de los momentos cumbres en lo que a representaciones se refiere. En aquel entonces, la crítica llegó a opinar que Goethe era más actualizable que Schiller, tal vez precisamente por su intemporalidad, o por ese rasgo que se le ha reconocido ya plenamente en nuestro siglo: su universalidad. ${ }^{5}$ Lo cierto es que Viena, París, Weimar, Hannover o Stuttgart figuraron entre los lugares escogidos para recrear el poema dramático de Goethe. Especial mención merece sin embargo el Fausto II, dirigido por Hans Günther Heyme, para quien esta segunda parte de la obra goethiana significaba el final del sentimiento revolucionario burgués. Fue aquella, en el Schauspielhaus de Colonia, y bajo una pomposa concepción escénica, una de las mejores realizaciones teatrales del mencionado año 1975.

Ya posteriormente, algunos de los momentos felices de escenificación de la obra cumbre de Goethe fueron las temporada 1979-80. Con un Fausto II, en el Residenztheater de Múnich, y con cuatro horas de duración, participaban setenta actores y un coro de de cincuenta voces. Asimismo en la temporada 81-82 hubo ocasión de presenciar el Faust en la Freie Volksbühne de Berlín; y en las temporadas 86-87 y 87-88 el Faust I, en el Münchner Kammerspiele, donde recibió unánime apoyo crítico la intérprete Sunnyl Melles. Destacable resultó también la temporada 89-90; entonces cosechó éxito en Cataluña con el título Jeu de Faust, en una creación del Théâtre du Radeau. Simultáneamente en aquellas fechas temporada 88-89/89-90- Italia, país muy receptivo en las últimas décadas a la dramaturgia alemana clásica de los siglos XVIII y XIX, fue lugar de representación de Faust, Frammenti parte prima, producción del Piccolo Teatro di Milano, dirigido por Giorgio Strehler, actor también en el papel de Fausto. Igualmente hubo ocasión de asistir a Faust, Frammenti parte seconda; y, en las temporadas 90-91/91-92, de nuevo en el Piccolo Teatro di Milano, destacando Franco Graziosi, Tino Carraro, Eleonora Brigliadori y Giulia Lazzarini como intérpretes, sobre una escenografía de Josef Svoboda y con figurines de Luisa Spinatelli.

\section{RECAPITULACIÓN}

Es evidente que los títulos clásicos de Goethe se representan asiduamente aquí y allá. Y es que ese rasgo típico de la comunicación literaria, que es el receptor universal consecuencia de dirigirse el emisor a un tú indiferenciado (Lázaro, 1987: 158), en el caso de Goethe y su teatro adquiere singular énfasis porque lo universal, mera abstracción teórica, se concreta en la realidad cotidiana, en los escenarios de hoy en día. Aun así, cierto es que por regla general en España no ha habido mucho interés por el drama goethiano ${ }^{6}$, pese a habernos

\footnotetext{
${ }^{5}$ En justa correspondencia con el goethiano concepto de Weltliteratur que, como alguien ha comentado, "se propone inventariar y explicar las obras maestras que constituyen el patrimonio de la humanidad, los títulos de gloria del planeta, todo aquello, en suma, que sin dejar de ser una nación, pertenece al conjunto de las naciones y sirve de equilibrado enlace entre lo nacional y lo supranacional." (Pichois, 1969: 118)

${ }^{6}$ Como tampoco el teatro goethiano parece haber ejercido influjo notable en la literatura española: “... los dramas de Goethe no han encontrado en la literatura española ningún eco duradero." (Rukser, 1977: 167). Ciertamente Faust quedaría un poco aparte de esta afirmación: "El influjo literario de Fausto es manifiesto en la obra de Espronceda (El diablo mundo, 1841) (...) en Bécquer (por ejemplo, Introducción sinfónica, 1868), Campoamor ( $E l$ licenciado Toralba, 1891), Benavente (Mefistófela, 1904) (...) Juan Valera (...) Fábula de Euforión (1844), Las
} 
tenido en mente el autor alemán especialmente en sus pimeros dramas. Si a Goethe lo conocemos de la mano de Madame de Staël y su célebre libro De l'Allemagne, de 1813, la primera atención hacia su teatro en nuestro país data de 1878, año de publicación de la monografía sobre él de Urbano González Serrano ${ }^{7}$, verdadero punto de arranque indispensable para el conocimiento de la crítica española sobre Goethe y su obra. Pese a todo, excepcionalmente, sí tuvo repercusión ya la obra teatral goethiana en la primera mitad del siglo XX: por ejemplo, el fragmento Nausikaa dio origen a la tragedia homónima del poeta Joan Maragall, escrita en su lengua catalana en 1910. De igual modo, hubo ya ocasión de ver teatro de Goethe en los escenarios españoles en las primeras dédadas del siglo, aunque realmente sólo de forma esporádica aparecían sus dramas en los escenarios de nuestro país. ${ }^{8}$ Afortunadamente, en la segunda mitad de siglo, y sobre todo en estos últimos años, las cosas han cambiado bastante; de hecho, recientes opiniones críticas españolas inciden en la incuestionable importancia que ha cobrado dentro del teatro contemporáneo no ya sólo el drama de Goethe, sino el teatro alemán en general.

En las carteleras alemanas, Goethe lógicamente está vivo de forma permanente. Pero además del alemán, públicos de diferentes culturas, como el italiano, el francés y, en menor medida, también el español, viene teniendo en las últimas décadas oportunidad de disfrutar con la dramaturgia goethiana; incluso algo similar puede decirse de otros países extraeuropeos, alguno de forma evidente, como Argentina.

Desde luego, la obra más repesentada es Fausto, seguida a mucha distancia, y por orden de mayor a menor representación, de Stella, Tasso e Iphigenie, que ocupan similar puesto en número de representaciones; y, finalmente, Götz, Clavigo y Die natürliche Tochter con parecida presencia en los escenarios teatrales.

En cuanto a la originalidad de la puesta en escena, la palma se la llevan Fausto y Götz von Berlichingen; esta última es especialmente meritoria precisamente por su dificultad de adaptación escénica.

En fin, a todas luces lo anterior no es más que un pequeño índice de lo que se puede trabajar en el campo de la vigencia del teatro de tiempos pasados. ${ }^{9}$ Por lo demás, y de igual modo que la investigación en el ámbito de la teoría e historia literarias -sobre todo cuando esas tareas investigadoras corren a cargo de docentes- en absoluto está reñida, sino todo lo contrario, con el afán por inculcar la lectura, por insistir en el disfrute que produce saborear

ilusiones del doctor Faustino (1875) -novela social en la que el titán Fausto queda reducido a un pequeño burguésy Morsamor (1899) (Hoffmeister, 1980: 162-163).

${ }^{7}$ Goethe, ensayos críticos. Madrid, 1878.

${ }^{8}$ Quizá esto tenga que ver con la relativa cultura teatral española; es decir, nuestra tradición en este sentido deja bastante que desear en comparación con Alemania, en donde es más habitual -incluso en poblaciones equiparables a pequeñas capitales de provincia españolas- asistir con cierta frecuencia a representaciones de teatro.

${ }^{9} \mathrm{Y}$ es que, además, el nacimiento de la metodología recepcional ha incidido en estudios de orden comparatístico interrelacionando aspectos sobre los que queda mucho por hacer: “...para la estética de la recepción, la consideración de la literatura es necesariamente supra e internacional, ya que las literaturas nacionales no existen como entidades independientes (Jauss, 1969)" (Moog-Grünewald, 1984: 78). 
la obra de arte confeccionada con lenguaje, cualquier indagación referida al mundo de la repesentación escénica -y junto al valor que en sí puedan aportar los resultados obtenidos, en este caso acerca el teatro goethiano- bien puede llevar aparejado el intento de contribuir a animar -más allá de la lectura- para que la asistencia a los teatros se convierta en hecho habitual; para que presenciar teatro llegue a ser una verdadera necesidad en unos tiempos en los que otras artes, o simplemente espectáculos, visuales acaparan abrumadoramente los espacios de ocio.

\section{BIBLIOGRAFÍA}

Arnold, H.L. (Hrsg.) (1982), Johann Wolfgang von Goethe, München, Text + Kritik (Sonderband)

Boerner, P. (1981), Johann Wolfgang von Goethe 1832-1982. Un ensayo biográfico, Bonn, Inter Nationes.

Enciclopedia Universal Ilustrada Europeo-Americana. Suplementos desde mediados los años cincuenta hasta 1998. Madrid-Barcelona, Espasa Calpe.

Gundolf, F. (1963), Goethe, Darmstadt, Wissenschaftliche Buchgesellschaft.

Hoffmeister, G. (1980), España y Alemania. Historia y documentación de sus relaciones literarias, Madrid, Gredos.

Lázaro Carreter, F. (1987), "La literatura como fenómeno comunicativo". En:

Pragmática de la comunicación literaria, Madrid, Arco/Libros (ed.: J.A.

Mayoral), 151-170.

Maurer-Schmoock, S. (1982), Deutsches Theater im 18. Jahrhundert, Tübingen, Max

Niemeyer Verlag.

Moog-Grünewald, M. (1984), "Investigación de las influenias y de la recepción”. En:

Teoría y praxis de la literatura comparada, Barcelona/Caracas, Editorial Alfa

(Manfred Schmeling et al.), 69-100.

Pageard, R. (1958), Goethe en españa, Madrid, Consejo Superior de Investigaciones Científicas.

Pichois, C./Rousseau, A.-M. (1969), La literatura comparada, Madrid, Gredos.

Rukser, U. (1977), Goethe en el mundo hispánico, México, Madrid, Buenos Aires, Fondo de Cultura Económica.

Theater der Zeit. Zeitschrift für Politik und Theater (Jun./93), Herausgegeben von 
Martin Linzer et al. Essen, Felidae Verlagsgesellschaft.

Theaterheute. Das Jahrbuch. Orell Füssli + Friedrich Verlag 1991. Erhard Friedrich

Verlag 1992. Erhard Friedrich Verlag in Zusammenarbeit mit Klett-Cotta

1993/94/95/96/97. Friedrich Berlin Verlag in Zusammenarbeit mit Klett-Cotta

1998/99. Varios números mensuales desde 1966 hasta 1999.

Trommler, F. (1984), “Goethe, Wagner und die Erneuerung des Theaters”. En: Goethe

im Kontext. Kunst und Humanität, Naturwissenschaft und Politik von der

Aufklärung bis zur Restauration. Ein Symposium, Tübingen, Max Niemeyer

Verlag, (ed.: W. Wittkowski), 163-180.

Zimmermann, B. (1974), "Der Leser als Produzent: Zur Problematik der

rezeptionsästhetischen Methode", Lili. Zeitschrift für Literaturwissenschaft und

Linguistik, 4.15, 12-26.

\section{APÉNDICE}

\section{En pos de la verdad}

"Probablemente Goethe nos da imagen de la máxima altura que puede alcanzar un hombre”, afirmaba Eugenio D'Ors. Desde luego, lo de menos es la efeméride; porque no hacen falta disculpas para evocar a cada instante el legado de personajes de renombre; para hacer de ellos permanente punto de referencia. Pero ya que no hace tanto se ha rememorado en Alemania, y aquí en España también -mediante reediciones y nuevas traducciones de su obra, congresos...-, la aportación goethiana con ocasión del ducentésimo quincuagésimo aniversario del nacimiento de ese alemán polígrafo y enciclopédico, bueno es echar un vistazo a su imagen, y ver cómo aquello que encarnaba, y que ejercitó en sus largos años de ininterrumpida creatividad, hoy se diluye tan fácilmente en el vacío ético encastrado en lo cotidiano; y quizá -al menos en parte- por "no haber seguido sus enseñanzas", como una vez lamentó el novelista Werner Bergengruen.

"Ver y tomar todas las cosas según son", decía esa persona extraordinaria en forma de poeta, pues así definió Thomas Mann a quien emulaba sin ambages: Johann Wolfgang von Goethe. Ubicuo, elfo bueno de la Humanidad, si la notoriedad que logró en vida llevó consigo el enaltecimiento y nombradía a la minúscula y entonces desconocida Weimar, su intemporalidad y grandeza jamás se disiparán en la caducidad de cuanto simboliza aquel que con tan poco se conformaba: una pequeña habitación para dormir y trabajar, y una frugal comida, según refiere un contemporáneo. Porque, con independencia de las dispares apreciaciones críticas habidas -no sin altibajos sobre todo en la pasada centuria- hacia su personalidad y creación literaria, la actualidad de la figura cimera, inmarcesible, del clasicismo alemán, romántico para muchos, está igual que siempre fuera de toda duda. 
Estadista al frente de las más diversas carteras ministeriales -y al margen de que se pueda o no simpatizar con su talante, neutralismo, convicciones personales, o con su retraimiento ante la Revolución francesa-, adoptó una actitud en el quehacer público casi en desuso en la vida política contemporánea, y bien extraña al discurso huero o a la tergiversación de eximios conceptos. Sin que haya que endiosarlo -ni a él ni a nadie, aconsejaba ya el filósofo Karl Jaspers, refiriéndose precisamente a Goethe-, justo es recordar que su intensísima actividad, en la cúspide de la Administración, la presidió -muy a pesar de críticas envidiosas- el sentido de la responsabilidad propio de un alma exquisita, el concepto abnegado de la labor pública y el deber para con la comunidad; nortes todos ellos que hoy -a una simple ojeada panorámica en nuestro derredor- llevan cuando menos a cuestionar si tal vez habrá fenecido el sentimiento límpido, excelso, en contacto con la ordinaria mediocridad.

Generosidad, ecuanimidad, armonía o ejemplaridad son valores inherentes a este paladín de la cultura, adalid de jóvenes intelectuales alemanes y circunstancial abogado, ávido además de una formación científica. Así es; Goethe había ido a la Universidad a hacerse jurista, pero aprovechó para aprender también otras muchas cosas asistiendo a clases de las más diversas materias. Porque el afán de conocimiento que siempre le embriagó, su "natural insatisfacción" -al decir de Ortega y Gasset-, era como la desmesurada vehemencia concupiscente del Fausto que él imaginó, pero en clave de sana ambición, evidenciada en la sinceridad del ser excepcionalmente genial.

Y es que Goethe realizó un sinfín de tareas: aprendió pintura y también dibujaba; asumió la dirección del Teatro de la Corte; halló semejanzas -desde la perspectiva de la evolución orgánica- entre el hombre y el mundo de los vertebrados, al descubrir el hueso intermaxilar en el ser humano, hasta entonces sólo conocido en los animales; fundamentó una teoría sobre el desarrollo y composición del cráneo; se opuso a Newton en sus estudios sobre óptica que, aunque con poca fortuna, llegaron a tener sin embargo adeptos de la talla de Hegel; contribuyó al desarrollo de Zoología y Botánica con precisiones sobre la metamorfosis de los seres vivos; aportó novedades a la Geología y Mineralogía, consecuencia de sus estudios como supervisor de minas y director de Institutos de Ciencias Naturales de la Universidad de Jena. ¡Incleíble! Claro que era otra época y que el desarrollo del conocimiento en poco puede compararse al de ahora; pero aun así, más de uno podría intuir si no se habrán acaso agostado ya tan hondas sensibilidades.

En ocasiones, y en los tiempos que corren, asistimos a un -mal encubierto- desdén hacia el saber, a la estrechez de miras y cicatería que hasta pone en duda filosofía o lenguas clásicas, baluartes del sistema educativo; nos topamos aquí y allá con miradas miopes e incomprensible, pacata, desconfianza hacia la cultura de Grecia y Roma; incluso, perplejos, escuchamos toda suerte de soflamas; y aquellos, para quienes lo que Goethe representa no pasa de ser una quimera, pretenden embaucar con el trastrueque de sublimes ideas morales. Goethe, muy al contrario, hizo suya esa Antigüedad que otros clásicos alemanes supieron también aprehender, no ya en su mero estatismo de fuente de conocimiento, sino como universo vigente de valores asumibles en armónica compatibilidad con el espíritu alemán.

Pero además, acercó el Oriente a la cultura europea. Acuñó el concepto de literatura universal, como universal es la poesía, la novela y el teatro por él creados: cúmulo de expe- 
riencias vitales, ininteligible en su más fina esencia sin el conocimiento de la biografía del autor, de su capacidad de amar fuera de lo común -rayana, eso sí, en lo extravagante- y de cuanto el amor tiene de fuerza irresistible, como bien experimentó el joven Werther, que dio nombre al primer "best seller" de la Historia de la Literatura; esa confesión, cuya originalísima forma epistolar unilateral asentó definitivamente la novelística alemana y trazó el camino de la escritura autobiográfica. De igual modo que en sus investigaciones y descubrimientos científicos se adelantaba al evolucionismo darwiniano, en el trabajo literario, y superando convenciones estéticas, evolucionó con tino y sin bruscas rupturas desde el romántico desasosiego juvenil hacia acrisoladas actitudes humanistas, en una vasta y atemperada obra supratemporal. Seguía así a la naturaleza y sus leyes; esa naturaleza que él tanto se empeñó en conocer y que escudriñó con ojos de esteta, y esas leyes universales que consideraba aplicables a todo: a la realidad física como a la moral humana, cuestión ésta subyacente en la novela a modo de punto de encuentro entre ciencia y literatura, disección del alma humana según los principios de la Química, que tan certeramente tituló Las afinidades electivas.

Cuando este trabajador infatigable profirió la celebérrima frase ¡Luz, más luz!, ya en el momento del estertor, llegaba a su fin quien en la existencia poetizó el ideal de belleza. Con peculiar religiosidad, estrechamente ligada al panteísmo de Spinoza, se había adornado de preciadas virtudes, a menudo ausentes por doquier: nobleza de pensamiento, repulsa hacia cualquier coerción, rechazo de posturas escépticas, sencillez, dignidad, intención educadora individual o colectiva y, sobre todo, incesante búsqueda de la verdad. Fue en Erfurt, en una cumbre diplomática adonde acudió en su calidad de Consejero áulico, cuando Napoleón, dirigiéndose a él, sentenció: -Vous êtes un homme!; el Emperador condensaba en aquella escueta y contundente aserción la hombría de bien del alemán excepcional, a quien nuestro siglo reconoció su dimensión universal, y que caminó toda su vida en pos de la verdad. 